\title{
Comparative protective assessments of some antioxidants against cyclophosphamide-induced kidney toxicity in albino rats
}

\author{
Elias Adikwu $^{1 * \mathbb{C}}$, Ebinyo C Nelson ${ }^{2}$, Abraham Singesi Yambozibe ${ }^{2}$ \\ ${ }^{1}$ Department of Pharmacology, Faculty of Basic Medical Sciences, University of Port Harcourt, Choba, Rivers State \\ ${ }^{2}$ Department of Pharmacology and Toxicology, Faculty of Pharmacy, Niger Delta University, Wilberforce Island, Bayelsa State
}

\section{AR T I C L E I N F O}

Article Type:

Original

\section{Article History:}

Received: 7 October 2018

Accepted: 16 December 2018

Published online: 13 January 2019

Keywords:

Cyclophosphamide

Kidney

Toxicity

Antioxidants

\begin{abstract}
A B S T R A C T
Introduction: Nephrotoxicity is one of the adverse effects of cyclophosphamide (CP).

Objectives: The aim of this study is to comparatively investigate the protective effects of melatonin (MT), alpha-lipoic acid (ALA) and N-acetylcysteine (NAC) on CP-induced nephrotoxicity in albino rats.

Materials and Methods: Sixty adult albino rats used for this study were divided into four groups (A-D). Rats in group A were treated with water intraperitoneally (ip) while rats in group B (B1-B4) were treated with NAC $(10 \mathrm{mg} / \mathrm{kg})$, ALA $(10 \mathrm{mg} / \mathrm{kg}), \mathrm{MT}(10 \mathrm{mg} / \mathrm{kg})$ and MT+ALA ip respectively for 5 days. Rats in group C were treated with CP $(150 \mathrm{mg} / \mathrm{kg})$ ip on day 5 . Rats in group D (D1D4) were pretreated with NAC, MT, ALA and MT+ALA ip for 5 days before treatment with CP on day 5 . Rats were sacrificed on the $6^{\text {th }}$ day. Serum was extracted from blood and evaluated for renal function parameters. Kidneys were removed and used for light microscopic and biochemical studies.

Results: CP-treated rats showed significant $(P<0.001)$ increases in serum creatinine, urea, uric acid, potassium, sodium, chloride bicarbonate and kidney malondialdehyde (MDA) levels while kidney superoxide dismutase (SOD), catalase (CAT), glutathione (GSH) and glutathione peroxidase (GPX) levels were significantly $(P<0.001)$ decreased when compared to control. Nephrotic changes characterized by tubular necrosis and infiltrations by inflammatory cells were observed in CPtreated rats. However, effects observed in $\mathrm{CP}$-treated rats were significantly abrogated in ALA $(P<0.05)$, MT $(P<0.05)$, NAC $(P<0.01)$ and MT+ALA $(P<0.001)$ pretreated rats when compared to $\mathrm{CP}$-treated rats.

Conclusion: The finding in this study showed that the nephroprotective effects of NA, MT, ALA, and MT+ALA can be ranked as MT+ALA $>$ NAC $>$ MT $>$ ALA.
\end{abstract}

Implication for health policy/practice/research/medical education:

This experimental study showed that $\mathrm{N}$-acetyl cysteine, melatonin and alpha lipoic acid had ameliorative impact on cyclophosphamide induced-nephrotoxicity and their nephroprotective effects can be ranked as MT+ALA $>$ NAC $>$ MT $>$ ALA.

Please cite this paper as: Adikwu E, Nelson EC, Yambozibe AS. Comparative protective assessments of some antioxidants against cyclophosphamide-induced kidney toxicity in albino rats. J Nephropharmacol. 2019;8(2):e22. DOI: 10.15171/npj.2019.22

\section{Introduction}

Cyclophosphamide (CP) is an alkylating agent belonging to the class of oxazaphosphorines (1). It is a potent anticancer agent that is effective against a wide spectrum of malignancies, such as leukemia, lymphoma, breast, lung, prostate, and ovarian cancers (2). Its metabolic activation through microsomal cytochrome $\mathrm{P} 450$ mixed functional oxidase pathway yields 4-hydroxy CP that exist in equilibrium with aldophosphamide, which is degraded by $\beta$-elimination to form phosphoramide mustard and the toxic byproduct, acrolein (3). Phosphoramide mustard brings about inter-strand cross-links between opposite DNA strands and prevents their replication and transcription process which characterize the clinical anti-cancer activity of CP (4) whereas acrolein has been associated with CP toxicities especially nephrotoxicity. Numerous studies have shown that acrolein can disrupt redox balance in the kidney leading to kidney damage (5). Nephrotoxicity due to $\mathrm{CP}$ can result in glomerular dysfunction, tubular dysfunction, and decrease in glomerular filtration rate (6).

Melatonin (N-acetyl-5-methoxytryptamine)

(MT), 
a circadian hormone mainly secreted by the pineal gland, is a derivative of tryptophan and predominantly secreted at night (7). It is also produced in the retina, thymus, bone marrow, respiratory epithelium, skin, lens, and intestine (8). It modulates a diverse number of physiological processes through receptor-mediated and receptor-independent mechanisms, thus, manifesting enormous functional versatility and diversity (9). MT and its metabolites have potent antioxidant and antiinflammatory properties and have been proven to be highly effective in a variety of disorders linked to inflammation and oxidative stress (10). MT can increase gene expression and enzyme activities of glutathione peroxidase (GPX), glutathione $(\mathrm{GSH})$ reductase, superoxide dismutase (SOD), and catalase (CAT) (11). It is an efficient protector of DNA, protein, and lipids in cellular membrane from endogenous and exogenous free radical generated during cellular processes $(12,13)$.

Alpha liopic acid is a natural antioxidant that palys a fundamental role in metabolism. It has been shown to affect cellular processes, alter redox status of cells, and interact with thiols and other antioxidants (14). It has beneficial effects on energy production, and is also an essential cofactor of mitochondrial complexes. It acts as coenzyme of pyruvate and alpha-ketoglutarate dehydrogenase multi-enzyme complex of tricarboxylic acid cycle (15). Moreover, ALA acts as an antioxidant that is fat and water soluble in both oxidized and reduced forms which allows it to concentrate in cellular and extracellular environments (16). Furthermore, ALA can regenerate other endogenous antioxidants (17) and has a unique property of neutralizing free radicals without it being consumed in the process (18). It is capable of preventing or treating many diseases associated with oxidative stress, such as diabetes, chronic liver diseases, and neurodegenerative processes (19).

$\mathrm{N}$-acetylcysteine (NAC) is a water soluble antioxidant that is a source of sulfhydryl groups in cells and due to its interaction with reactive oxygen species; it is a scavenger of free radicals (20). NAC is one of the large groups of exogenous antioxidants that protects against oxidative tissue injury. This effect may be directly related to its free radical scavenging property or to the secondary induction of GSH production (21). It protects mitochondrial from damage, inhibits lipid peroxidation (LPO) and cellular damage (22). It enhances many cellular defense mechanisms and enriches cellular GSH level by acting as a precursor in the GSH synthesis pathway (22). Furthermore, NAC is capable of restoring impaired prooxidant/antioxidant balance and has been widely used as an effective antioxidant against oxidative stress both in vivo and in vitro (23).

\section{Objectives}

The present study aimed to assess the comparative nephroprotective effects of NAC, MT, ALA against CP- induced kidney damage in a rat model.

\section{Materials and Methods \\ Experimental animals}

Adult albino rats with an average weight of $200 \pm 5 \mathrm{~g}$ used for this research were housed in cages ( 6 per cage) and allowed to acclimatize for 2 weeks in a well ventilated room. The rats were fed with standard rodents chow and given tap water ad labium. All animals used for this study were handled in accordance with the regulations promulgated by the Canadian Council of Animal Care (2009) (24).

\section{Drugs and chemicals}

The dose of CP (150 mg/kg), MT (10 mg/kg), NAC (10 $\mathrm{mg} / \mathrm{kg})$ and ALA $(10 \mathrm{mg} / \mathrm{kg})$ were used for this study (25-28). All other chemicals used for this study are of analytical grade.

\section{Grouping of animals}

Sixty adult rats were grouped into four groups A to D. Group A contained six rats while group B was divided into subgroups B1to B4 of six rats each. Group C contains six rats while group D was divided into subgroups D1 to D4 of six rats each.

\section{Experimental protocol}

Group A was treated with water intraperitoneally (ip) while rats in group B (B1-B4) were treated with NAC (10 mg/kg/d), ALA (10 mg/kg/d), MT (10 mg/kg/d) and $\mathrm{MT}+\mathrm{ALA}$ ip respectively for 5 days. Rats in group $\mathrm{C}$ were treated with CP $(50 \mathrm{mg} / \mathrm{kg} / \mathrm{d})$ ip on day 5 . Rats in group D (D1-D4) were pretreated with NAC, MT, ALA and MT+ALA ip for 5 days before treatment with CP ip on day 5 .

\section{Sacrifice and sample collection}

At the end of drug administration, the rats were sacrificed using diethyl ether as anesthesia. Blood samples were collected from the heart and centrifuged at $1500 \mathrm{rpm}$ for 20 minutes and serum extracted and evaluated for markers of renal function. The kidneys were collected and rinsed in an ice cold $1.15 \% \mathrm{KCl}$ solution. The kidneys were homogenized with $0.1 \mathrm{M}$ phosphate buffer $(\mathrm{pH} 7.2)$ and centrifuged at $1200 \mathrm{rpm}$ for 20 minutes. The supernatant was decanted and evaluated for markers of oxidative stress

\section{Evaluation of renal function parameters and oxidative stress indices \\ Serum creatinine, urea, uric acid, bicarbonate, albumin and total protein content were assayed using standard laboratory technique and reagents. Potassium and sodium were determined using flame photometric methods, while chloride levels were determined using titrimetric methods. SOD was evaluated according to Sun and Zigma (29), CAT was evaluated as described by Sinha et al, 1972}


(30). Reduced GSH was measured as reported by Sedlak and Lindsay (31), while the method of Rotruck et al (32) was used for the evaluation of GPX. Malondialdehyde (MDA) was evaluated according to Buege et al (33).

\section{Ethical issues}

This project was approved by Ethics Committee of the Department of Pharmacology and Toxicology, Faculty of Pharmacy, Niger Delta University, Bayelsa State, Nigeria. Prior to the experiment, the protocols were confirmed to be in accordance with the guidelines of Animal Ethics Committee of Niger Delta University.

\section{Statistical analysis}

Statistical analysis was performed using SPSS 18 software (SPSS Inc, Chicago, IL). Results are expressed as mean \pm standard error of mean (SEM). Mean of groups were compared using ANOVA and Tukey's post hoc test. Significance was set at $P<0.05 ; 0.01$.

\section{Results}

The administration of NAC, MT and ALA did not produce significant $(P>0.05)$ effects on body, kidney weighs, serum urea, uric acid, creatinine, total protein, and albumin levels in comparison to control (Tables 1 and 2). In contrast, serum levels of urea, uric acid, creatinine were increased significantly $(P<0.001)$ whereas total protein, and albumin were significantly $(P<0.001)$ decreased in CP-treated rats when compared to control. However rats pretreated with individual doses of MT and ALA showed significant $(P<0.05)$ decreases in serum levels of urea, uric acid, creatinine whereas total protein, and albumin were significantly $(P<0.05)$ increased when compared to CP-treated rats. Interestingly, effects observed on the above parameters most evident in rats pretreated with NAC $(P<0.01)$ and MT +ALA $(P<$ 0.001 ) when compared to $\mathrm{CP}$ - treated rats (Table 2). Furthermore, the administration of NAC, MT and ALA had no significant $(P>0.05)$ effects on serum electrolytes
$\left(\mathrm{Na}+, \mathrm{Cl}^{-}, \mathrm{K}^{+}, \mathrm{HCO}^{-}\right)$when compared to control. However, there were significant $(P<0.001)$ alterations in serum electrolytes in $\mathrm{CP}$-treated rats when compared to control. Notwithstanding, serum electrolytes were significantly $(P<0.05)$ restored in individual doses of MT and ALA pretreated rats in comparison to CP-treated rats. Most significant restorations in serum electrolytes were observed in rats pretreated with NAC $(P<0.01)$ and MT + ALA $(P<0.001)$ in comparison to CP-treated rats (Table 3). Furthermore, the administration of NAC, MT and ALA had no significant $(P>0.05)$ effects on kidney MDA, CAT, SOD, GSH, and GPX levels when compared to control. On the other hand, there was significant $(P<0.001)$ increase in MDA level whereas CAT, SOD, GSH, and GPX levels were significantly $(P<0.001)$ decreased in $\mathrm{CP}$ - treated rats when compared to control. In contrast, pretreatment with individual doses of MT and ALA significantly $(P<0.05)$ decreased MDA levels with significant $(P<0.05)$ increases in CAT, SOD, GSH and GPX levels when compared to CP-treated rats. It is fascinating that effects on the above parameters were most pronounced in rats pretreated with NAC $(P<0.01)$ and MT+ALA $(P<0.001)$ when compared to $C P$-treated rats (Table 4$)$. Furthermore, the kidney of the control rats showed normal histology (Figure 1A) whereas the kidney of rat treated with CP showed tubular necrosis and infiltrations by inflammatory cells (Figure 1B). On the other hand, the kidneys of rats pretreated with NAC, MT, ALA and MT+ALA respectively before treatment with CP showed normal histology (Figures 1C to $1 \mathrm{~F})$.

\section{Discussion}

Oxidative stress can be defined as an imbalance between oxidants and antioxidants characterized by disturbance in the pro-oxidant-antioxidant balance in favor of the oxidant, leading to biomolecular damage (34). Studies have demonstrated that oxidative stress could be a key mechanism in drug-induced renal toxicity (35). This study aimed at investigating the comparative protective effects

Table 1. Effects of NAC, MT, and ALA on body and kidney weights of CP-treated albino rats

\begin{tabular}{|c|c|c|c|c|}
\hline Treatment & Initial body weight (g) & Final body weight (g) & Kidney weight (g) & Relative kidney weight (\%) \\
\hline Control & $220.6 \pm 13.0$ & $225.9 \pm 10.7$ & $0.76 \pm 0.06$ & $0.34 \pm 0.02$ \\
\hline NAC & $200.8 \pm 11.7$ & $212.5 \pm 10.0$ & $0.80 \pm 0.08$ & $0.37 \pm 0.06$ \\
\hline MT & $210.6 \pm 12.1$ & $221.1 \pm 14.6$ & $0.76 \pm 0.02$ & $0.34 \pm 0.01$ \\
\hline ALA & $218.8 \pm 10.9$ & $225.6 \pm 11.7$ & $0.81 \pm 0.08$ & $0.36 \pm 0.03$ \\
\hline $\mathrm{MT}+\mathrm{ALA}$ & $220.1 \pm 14.6$ & $229.0 \pm 12.2$ & $0.78 \pm 0.07$ & $0.34 \pm 0.04$ \\
\hline $\mathrm{CP}$ & $215.4 \pm 13.6$ & $220.4 \pm 12.6$ & $0.88 \pm 0.02$ & $0.40 \pm 0.08$ \\
\hline $\mathrm{CP}+\mathrm{NAC}$ & $220.6 \pm 14.3$ & $226.8 \pm 10.1$ & $0.79 \pm 0.09$ & $0.35 \pm 0.03$ \\
\hline $\mathrm{CP}+\mathrm{MT}$ & $209.8 \pm 10.7$ & $217.7 \pm 13.3$ & $0.87 \pm 0.07$ & $0.40 \pm 0.01$ \\
\hline$C P+A L A$ & $221.9 \pm 11.9$ & $230.2 \pm 10.7$ & $0.88 \pm 0.05$ & $0.38 \pm 0.02$ \\
\hline $\mathrm{CP}+\mathrm{MT}+\mathrm{ALA}$ & $210.2 \pm 13.2$ & $221.2 \pm 13.5$ & $0.83 \pm 0.09$ & $0.38 \pm 0.05$ \\
\hline
\end{tabular}

CP; cyclophosphamide, NAC; N-acetylcysteine, MT; melatonin, ALA; alpha lipoic acid.

Data are expressed as mean $\pm \operatorname{SEM}(n=6)$. 
Adikwu et al

Table 2. Effects of NAC, MT, and ALA on serum renal function parameters of CP- treated albino rats

\begin{tabular}{|c|c|c|c|c|c|}
\hline Treatment & Urea (mg/dL) & Creatinine (mg/dL) & Uric acid (mg/dL) & Total protein (g/dL) & Albumin (g/dL) \\
\hline Control & $22.3 \pm 2.20$ & $2.36 \pm 0.13$ & $2.72 \pm 0.32$ & $9.40 \pm 0.71$ & $5.55 \pm 0.20$ \\
\hline NAC & $20.0 \pm 2.11$ & $2.21 \pm 0.14$ & $2.50 \pm 0.21$ & $9.61 \pm 0.53$ & $5.57 \pm 0.11$ \\
\hline MT & $21.6 \pm 2.00$ & $2.30 \pm 0.11$ & $2.63 \pm 0.73$ & $9.52 \pm 0.44$ & $5.65 \pm 0.30$ \\
\hline ALA & $22.0 \pm 2.62$ & $2.35 \pm 0.10$ & $2.69 \pm 0.44$ & $9.48 \pm 0.21$ & $5.55 \pm 0.72$ \\
\hline $\mathrm{MT}+\mathrm{ALA}$ & $20.5 \pm 2.43$ & $2.25 \pm 0.24$ & $2.55 \pm 0.41$ & $9.78 \pm 0.55$ & 5. $78 \pm 0.43$ \\
\hline $\mathrm{CP}$ & $99.12 \pm 5.13^{\mathrm{a}}$ & $7.94 \pm 0.35^{\mathrm{a}}$ & $7.53 \pm 0.10^{a}$ & $2.03 \pm 0.41^{\mathrm{a}}$ & $1.87 \pm 0.09^{a}$ \\
\hline $\mathrm{CP}+\mathrm{NAC}$ & $30.3 \pm 3.22^{b}$ & $3.75 \pm 0.08^{b}$ & $3.10 \pm 0.09^{b}$ & $6.18 \pm 0.71^{b}$ & $4.14 \pm 0.92^{b}$ \\
\hline $\mathrm{CP}+\mathrm{MT}$ & $62.8 \pm 2.04^{c}$ & $4.75 \pm 0.32^{c}$ & $4.45 \pm 0.32^{c}$ & $4.47 \pm 0.52^{c}$ & $3.55 \pm 0.73^{c}$ \\
\hline$C P+A L A$ & $65.7 \pm 3.19^{c}$ & $4.73 \pm 0.60^{c}$ & $4.99 \pm 0.41^{c}$ & $3.99 \pm 0.42^{c}$ & $3.41 \pm 0.42^{c}$ \\
\hline $\mathrm{CP}+\mathrm{MT}+\mathrm{ALA}$ & $35.2 \pm 2.45^{b}$ & $2.10 \pm 0.22^{d}$ & $2.31 \pm 0.22^{d}$ & $8.00 \pm 0.11^{d}$ & $5.07 \pm 0.40^{d}$ \\
\hline
\end{tabular}

CP; cyclophosphamide, NAC; N-acetylcysteine, MT; melatonin, ALA; alpha lipoic acid.

Data are expressed as mean $\pm \operatorname{SEM}(n=6)$.

${ }^{a}$ Significant $(P<0.001)$ difference when compared to control; ${ }^{b}$ Significant $(P<0.01)$ difference when compared to CP-treated rats; ${ }^{c}$ Significant $(P<0.05)$

difference when compared to CP-treated rats; ${ }^{\mathrm{d}}$ Significant $(P<0.001)$ difference when compared to CP-treated rats.

Table 3. Effects of NAC, MT, and ALA on serum electrolytes of CP-treated albino rats

\begin{tabular}{|c|c|c|c|c|}
\hline Treatment & $\mathrm{K}^{+}(\mathrm{mmo} / \mathrm{L})$ & $\mathrm{Cl}$ (mmo/L) & $\mathrm{Na}^{+}(\mathrm{mmo} / \mathrm{L})$ & $\mathrm{HCO}^{-}(\mathrm{mmo} / \mathrm{L})$ \\
\hline Control & $3.54 \pm 0.61$ & $120.4 \pm 6.11$ & $170.5 \pm 7.42$ & $20.6 \pm 2.21$ \\
\hline NAC & $3.50 \pm 0.72$ & $121.0 \pm 7.29$ & $175.2 \pm 6.51$ & $21.4 \pm 2.32$ \\
\hline MT & $3.52 \pm 0.67$ & $123.4 \pm 6.43$ & $174.1 \pm 8.43$ & $19.8 \pm 1.30$ \\
\hline ALA & $3.51 \pm 0.71$ & $125.2 \pm 7.54$ & $172.7 \pm 9.23$ & $20.7 \pm 1.25$ \\
\hline $\mathrm{MT}+\mathrm{ALA}$ & $3.63 \pm 0.44$ & $122.9 \pm 9.53$ & $170.6 \pm 7.43$ & $18.2 \pm 1.47$ \\
\hline $\mathrm{CP}$ & $9.67 \pm 0.30^{\mathrm{a}}$ & $679.8 \pm 8.77^{a}$ & $698.9 \pm 8.32^{a}$ & $40.9 \pm 3.30^{\mathrm{a}}$ \\
\hline$C P+N A C$ & $4.70 \pm 0.25^{b}$ & $300.0 \pm 6.14^{b}$ & $340.8 \pm 8.42^{b}$ & $20.9 \pm 2.13^{b}$ \\
\hline $\mathrm{CP}+\mathrm{MT}$ & $6.12 \pm 0.77^{c}$ & $435.3 \pm 9.40^{c}$ & $421.4 \pm 7.00^{c}$ & $28.0 \pm 2.11^{c}$ \\
\hline $\mathrm{CP}+\mathrm{ALA}$ & $6.33 \pm 0.68^{c}$ & $456.4 \pm 7.33^{c}$ & $435.5 \pm 8.17^{c}$ & $30.2 \pm 2.00^{c}$ \\
\hline $\mathrm{CP}+\mathrm{MT}+\mathrm{ALA}$ & $3.82 \pm 0.56^{d}$ & $235.6 \pm 8.42^{d}$ & $330.8 \pm 9.22^{b}$ & $21.8 \pm 2.22^{b}$ \\
\hline
\end{tabular}

CP; cyclophosphamide, NAC; N-acetylcysteine, MT; melatonin, ALA; alpha lipoic acid.

Data are expressed as mean $\pm \operatorname{SEM}(n=6)$.

a Significant $(P<0.001)$ difference when compared to control; ${ }^{b}$ Significant $(P<0.01)$ difference when compared to $C P$-treated rats; ${ }^{c}$ Significant $(P<0.05)$ difference when compared to CP-treated rats; ${ }^{\mathrm{d}}$ Significant $(P<0.001)$ difference when compared to CP-treated rats.

Table 4. Effects of NAC, MT, and alpha lipoic acid on kidney oxidative stress markers of cyclophosphamide-treated albino rats

\begin{tabular}{|c|c|c|c|c|c|}
\hline Treatment & MDA (nmol/mg protein) & GSH ( $\mu \mathrm{g} / \mathrm{mg}$ protein) & CAT (U/mg protein) & SOD (U/mg protein) & GPX (U/mg protein) \\
\hline Control & $0.27 \pm 0.09$ & $10.1 \pm 0.70$ & $30.7 \pm 2.00$ & $24.0 \pm 2.00$ & $26.3 \pm 2.10$ \\
\hline NAC & $0.25 \pm 0.06$ & $10.5 \pm 0.84$ & $34.6 \pm 3.14$ & $27.4 \pm 2.40$ & $29.0 \pm 1.24$ \\
\hline MT & $0.26 \pm 0.02$ & $10.3 \pm 1.0$ & $32.2 \pm 3.28$ & $25.7 \pm 2.51$ & $27.3 \pm 1.00$ \\
\hline ALA & $0.25 \pm 0.02$ & $10.2 \pm 0.52$ & $32.3 \pm 3.11$ & $25.6 \pm 2.56$ & $26.4 \pm 2.13$ \\
\hline $\mathrm{MT}+\mathrm{ALA}$ & $0.24 \pm 0.07$ & $10.4 \pm 0.67$ & $34.0 \pm 3.15$ & $26.3 \pm 2.17$ & $29.1 \pm 2.23$ \\
\hline $\mathrm{CP}$ & $2.68 \pm 0.13^{\mathrm{a}}$ & $2.46 \pm 0.18^{a}$ & $9.34 \pm 0.82^{\mathrm{a}}$ & $7.29 \pm 0.33^{\mathrm{a}}$ & $8.05 \pm 1.00^{\mathrm{a}}$ \\
\hline $\mathrm{CP}+\mathrm{NAC}$ & $0.31 \pm 0.07^{b}$ & $6.98 \pm 0.64^{b}$ & $20.8 \pm 2.11^{b}$ & $18.6 \pm 2.86^{b}$ & $18.0 \pm 1.25^{b}$ \\
\hline $\mathrm{CP}+\mathrm{MT}$ & $1.54 \pm 0.01^{c}$ & $4.99 \pm 0.37^{c}$ & $16.7 \pm 1.43^{c}$ & $13.4 \pm 1.60^{c}$ & $14.2 \pm 1.32^{c}$ \\
\hline$C P+A L A$ & $1.60 \pm 0.06^{c}$ & $4.75 \pm 0.55^{c}$ & $15.5 \pm 1.22^{c}$ & $12.2 \pm 0.17^{c}$ & $14.9 \pm 2.17^{c}$ \\
\hline $\mathrm{CP}+\mathrm{MT}+\mathrm{ALA}$ & $0.33 \pm 0.01^{b}$ & $9.57 \pm 0.52^{d}$ & $25.1 \pm 3.34^{d}$ & $23.2 \pm 2.00^{d}$ & $22.2 \pm 3.37^{d}$ \\
\hline
\end{tabular}

CP; cyclophosphamide, NAC; N-acetylcysteine, MT; melatonin, ALA; alpha lipoic acid.

Data are expressed as mean $\pm \operatorname{SEM}(n=6)$.

a Significant $(P<0.001)$ difference when compared to control; ${ }^{b}$ Significant $(P<0.01)$ difference when compared to CP-treated rats; ${ }^{c}$ Significant $(P<0.05)$ difference when compared to $C P$-treated rats; d Significant $(P<0.001)$ difference when compared to CP-treated rats.. 

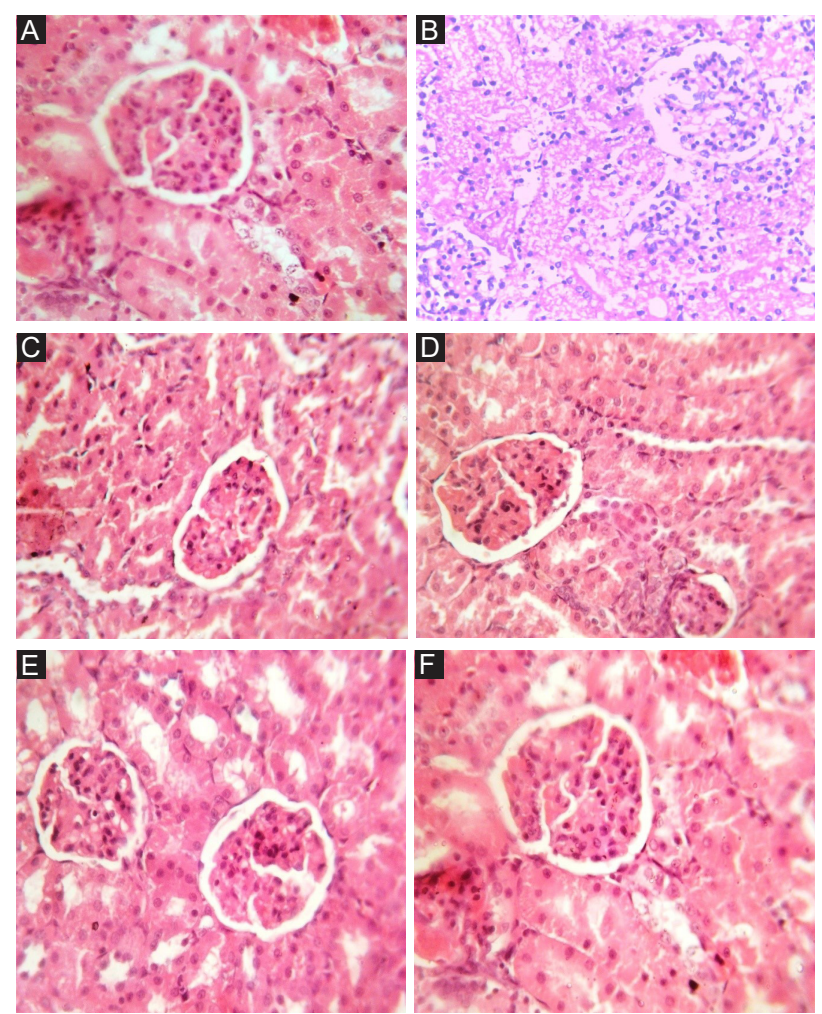

Figure 1. (A) Kidney of control rat showing normal histology. (B) Kidney of rat treated with cyclophosphamide showing tubular necrosis and infiltrations by inflammatory cells. (C to F) Kidney of rats treated with NAC, melatonin, and alpha lipoic acid respectively before the administration of cyclophosphamide showing normal histology. (F) Kidney of rats treated with a combination of melatonin, and alpha lipoic acid before the administration of cyclophosphamide showing normal histology.

of ALA, NAC and MT on CP-induced nephrotoxicity in albino rats. Perturbations in body and organ weights are signs that could characterize CP-induced renal toxicity (36). However, the nephrotoxic effect of CP-observed in this study was not marked by alterations in body and kidney weights. Renal function assessment involves the measurement of serum creatinine, urea and uric acid concentrations (37). In the present study, the serum levels of creatinine, urea, and uric acid were not altered in ALA, MT and NAC treated rats. The observations are in agreement with previous reports (38). On the other hand, the serum levels of creatinine, urea and uric acid were elevated in CP administered rats. The observations are consistent with previous findings (39). The elevated levels of these parameters are evidence of renal dysfunction in CP-treated rats. This could be attributed to decreased excretion of creatinine, urea and uric acid due to decreased glomerular filtration rate in CP-treated rats (40). However, the serum levels of creatinine, urea and uric acid were restored in MT, ALA and NAC pretreated rats. Serum total protein and albumin are biochemical indexes for the assessment of kidney function especially in malnourished situations $(41,42)$. CP-treated rats showed decreased serum levels of albumin and total protein. This is an evidence of compromise kidney function which has been earlier reported (43). Interestingly, the serum levels of albumin and total protein were restored with MT, NAC and ALA pretreatments. CP associated renal toxicity is often characterized by perturbations in kidney antioxidant defense and LPO (44). In this study, CPtreated rats showed perturbations in kidney antioxidants characterized by decreases in the levels of SOD, GPX, CAT and GSH with increases in MDA levels. This finding is an evidence of oxidative kidney damage (45). However, the kidney levels of SOD, GPX, CAT, GSH and MDA levels were restored in ALA, MT and NAC pretreated rats. Furthermore, serum electrolytes play an important role in many body processes, such as controlling fluid levels, acid-base balance, nerve conduction, blood clotting and muscle contraction (46). Renal toxicity due to CP is often associated with perturbations in serum electrolytes (47). In this study, serum electrolytes were elevated in CP-treated albino rats. However, serum electrolytes were restored in MT, ALA and NAC pretreated rats. Kidney histological examination contributes to diagnostic accuracy in druginduced kidney damage and remains a valuable tool in assessing drug-induced kidney damage (48). CP renal pathology is often characterized by necrotic changes in kidney structure (49). This study observed kidney pathologic changes characterized by tubular necrosis, and infiltrations by inflammatory cells in CP-treated rats. However, these pathologic changes were ameliorated in rats pretreated with MT, ALA and NAC.

The precise mechanism by which $\mathrm{CP}$ causes renal injury is poorly known. However, studies have attributed it to its cytotoxic metabolite; acrolein (50). Acrolein is a highly reactive, unsaturated aldehyde that induces LPO and changes intracellular redox balance (51). Acrolein, when filtered in the kidney into urine, induces a cascade of pro-inflammatory processes, and stimulates oxidative and nitrosative stress which can lead to kidney damage $(52,53)$. MT, ALA and NAC might have inhibited CPinduced oxidative kidney damage through scavenging, neutralizing and mopping-up of free radicals generated by $\mathrm{CP}$ and its metabolites. NAC is a small water-soluble molecule containing a thiol group, which has antioxidant property. It replenishes GSH store, increases SOD activity, scavenges hydroxyl free radical and inhibits LPO (54). MT is an effective antioxidant that scavenges free radicals. It scavenges highly toxic hydroxyl radical, and peroxynitrite anion. Also, it scavenges superoxide anion radical, quenches singlet oxygen and inhibits oxidative stress induced biomolecular damage. MT can increase mRNA and protein levels of antioxidant enzymes through nuclear-related factor 2 activation (55). It is capable of penetrating into mitochondria and exerting protection against various pathological conditions induced by oxidative stress $(56,57)$. ALA is a naturally occurring 
dithiol compound that functions as an essential cofactor for mitochondrial bio-energetic enzymes (58). ALA and its reduced form, (dihydrolipoic acid), have antioxidant activity in fat- and water-soluble media. ALA can react with superoxide, hydroxyl radicals, hypochlorous acid, peroxyl radicals, and singlet oxygen thereby inhibiting their detrimental actions. Experimentally, it has been used for the treatment of various pathological conditions associated with oxidative stress (59).

\section{Conclusion}

This study demonstrated that the nephroprotective effects of NAC, MT, ALA and MT+ALA against CP-intoxicated rats can be ranked as $\mathrm{MT}+\mathrm{ALA}>\mathrm{NAC}>\mathrm{MT}>\mathrm{ALA}$.

\section{Authors' contribution}

EA; Concept and design of the study, literature search, collection of data, statistical analysis, and manuscript preparation. ECN; Concept, collection of data, review of the literature, and preparation of first manuscript draft. ASY; Concept, collection of data, review of the literature, preparation of first manuscript draft and critical revision of the manuscript

\section{Acknowledgements}

The authors appreciate the technical support of Mr. Obi Cosmos of the Department of Pharmacology and toxicology, Faculty of Pharmacy, Niger Delta University, Nigeria.

\section{Conflicts of interest}

Authors declare no conflicts of interest.

\section{Ethical considerations}

Ethical issues (including plagiarism, data fabrication, double publication) have been completely observed by the authors.

\section{Funding/Support}

None.

\section{References}

1. Oh MS, Chang MS, Park W, Kim DR, Bae H, Huh Y, et al. Yukmijihwang-tang . protects against cyclophosphamideinduced reproductive toxicity. Reprod Toxicol. 2007;24:365-70.

2. Khan TS, Sundin A, Juhlin C, Wilander E, Öberg K, Eriksson B. Vincristine, cisplatin, teniposide, and cyclophosphamide combination in the treatment of recurrent or metastatic adrenocortical cancer. Med Oncol. 2004;21:167-77.

3. Pass GJ, Carrie D, Boylan M, Lorimore S, Wright E, Houston B, et al. Role of hepatic cytochrome P450s in the pharmacokinetics and toxicity of cyclophosphamide: studies with the hepatic cytochrome P450 reductase null mouse. Canc Res. 2005;65:4211-7.

4. Di Paolo A, Danesi R, Del Tacca M. Pharmacogenetics of neoplastic diseases: New trends. Pharmacol Res. 2004;49:331-42.

5. Nafees S, Rashid S, Ali N, Hasan SK, Sultana S. Rutin ameliorates cyclophosphamide induced oxidative stress and inflammation in Wistar rats: role of NFKB/MAPK pathway. Chem Biol Interact. 2015;231:98-107.

6. Sugumar E, Kanakasabapathy I, Abraham P. Normal plasma creatinine level despite histological evidence of damage and increased oxidative stress in the kidneys of cyclophosphamide treated rats. Clin Chim Acta. 2007;376:244-5.

7. Singh M, Jadhav HR. Melatonin: functions and ligands. Drug Discov Today. 2014;19:1410-8.

8. Tan DX, Manchester LC, Terron MP, Flores LJ, Reiter RJ . One molecule, many derivatives: a never-ending interaction of melatonin with reactive oxygen and nitrogen species? J Pineal Res. 2007;42:28-42.

9. Reiter RJ, Tan DX, Burkhardt S. Reactive oxygen and nitrogen species and cellular and organismal decline: amelioration with melatonin. Mech Ageing Dev. 2002;123:1007-19.

10. Reiter RJ, Tan DX, Jou MJ, Korkmaz A, Manchester LC, Paredes SD. Biogenic amines in the reduction of oxidative stress: melatonin and its metabolites. Neuro Endocrinol Lett. 2008;29:391-8.

11. Carpentieri A, Díaz de Barboza G, Areco V, Peralta López $\mathrm{M}$, Tolosa de Talamoni N. New perspectives in melatonin uses. Pharmacol Res. 2012;65:437-444.

12. Cuzzocrea S, Reiter RJ. Pharmacological action of melatonin in shock, inflammation and ischemia/ reperfusion injury. Eur J Pharmacol. 2001;426:1-10.

13. Zang LY, Cosma G, Gardner H, Vallyathan V. Scavenging of reactive oxygen species by melatonin. Biochim Biophys Acta. 1998;1425:469-77.

14. Packer L, Witt EH, Tritschler HJ. Alpha-lipoic acid as a biological antioxidant. Free Radic Biol Med. 1995;19:22750.

15. Bulut NE, Özkan E, Ekinci O, Dulundu E, Topaloğlu Ü, Şehirli AÖ, et al. Beneficial effects of alpha lipoic acid on cerulein-induced experimental acute pancreatitis in rats. Ulus Travma Acil Cerrahi Derg. 2011;17:383-9.

16. Kagan VE, Shvedova A, Serbinova E, Khan S, Swanson C, Powell R, et al. Dihydrolipoic acid-a universal antioxidant both in the membrane and in the aqueous phase: Reduction of peroxyl, ascorbyl and chromanoxyl radicals. Biochem Pharmacol. 1992;44:1637-49.

17. Bast A, Haenen GR. Lipoic acid, a multifunctional antioxidant. Biofactors. 2003;17:207-13.

18. Shay KP, Moreau RF, Smith EJ, Smith AR, Hagen TM. Alpha-lipoic acid as a dietary supplement: molecular mechanisms and therapeutic potential. Biochim Biophys Acta. 2009;1790:1149-60.

19. Smith AR, Shenvi SV, Widlansky M, Suh JH, Hagen TM. Lipoic acid as a potential therapy for chronic diseases associated with oxidative stress. Curr Med Chem. 2004;11:1135-46.

20. Zafarullah M, Li WQ, Sylvester J, Ahmad M. Molecular mechanisms of $\mathrm{N}$-acetylcysteine actions. Cell Mol Life Sci. 2003;60:6-20.

21. Fishbane S, Durham JH, Marzo K, Rudnick M. 
$\mathrm{N}$-acetylcysteine in the prevention of radiocontrast induced nephropathy. J Am Soc Nephrol. 2004;15:25160.

22. Samuni Y, Goldstein S, Dean OM, Berk M. The chemistry and biological activities of $N$-acetylcysteine. Biochim Biophys Acta. 2013;1830:4117-29.

23. Yalcin S, Bilgili A, Onbasilar I, Eraslan G, Ozdemir M. Synergistic action of sodium selenite and $N$-acetylcysteine in acetaminophen induced liver damage. Hum Exp Toxicol. 2008;27:425-9.

24. Canadian Council on Animal Care. Guidelines on: the care and use of experimental animals in research, teaching and testing. Ottawa, ON: CCAC; 2009.

25. Estakhri R, Hajipour B, Majidi H, Soleimani H. Vitamin E ameliorates cyclophosphamide induced nephrotoxicity. Life Sci J. 2013;10:308-313.

26. Hrenák J, Arendášová $K$, Rajkovičová R, Aziriová $S$, Repová K, Krajčírovičová $\mathrm{K}$, et al. Protective effect of captopril, olmesartan, melatonin and compound 21 on doxorubicin-induced nephrotoxicity in rats. Physiol Res. 2013;62:S181-9.

27. Meeran MFN, Prince PSM, Basha RH. Preventive effects of $\mathrm{N}$-acetyl cysteine on lipids, lipoproteins and myocardial infarct size in isoproterenol induced myocardial infarcted rats: an in vivo and in vitro study. Eur J Pharmacol. 2012;677:116-22.

28. Guven A, Tunc T, Topal T, Kul M, Korkmaz A, Gundogdu G, et al. Alpha-lipoic acid and ebselen prevent ischemia/ reperfusion injury in the rat intestine. Surg Today. 2008;38:1029-35.

29. Sun M, Zigman S. An improved spectrophotometric assay for superoxide dismutase based on epinephrine autoxidation. Anal Biochem. 1978;90:81-9.

30. Sinha AK. Colorimetric assay of catalase. Anal Biochem. 1972;47:389-94.

31. Sedlak J, Lindsay RH. Estimation of Total, ProteinBound, and Nonprotein Sulfhydryl Groups in Tissue with Ellman's Reagent. Anal Biochem. 1968;25:192-205.

32. Rotruck JT, Rope AL, Ganther HF, Swason AB. Selenium: biochemical role as a component of glutathione peroxidase. Science. 1973;179:588-90.

33. Buege JA, Aust SD. Microsomal Lipid Peroxidation. Methods Enzymol. 1978;52:302-10.

34. Sies H. Oxidative stress: from basic research to clinical application. Am J Med.1991;91:31-8.

35. Santos NA, Catão CS, Martins NM, Curti C, Bianchi ML, Santos AC. Cisplatin-induced nephrotoxicity is associated with oxidative stress, redox state unbalance, impairment of energetic metabolism and apoptosis in rat kidney mitochondria. Arch Toxicol. 2007;81:495-504.

36. Omole JG, Ayoka OA, Alabi QK, Adefisayo MA, Asafa MA. Protective Effect of Kolaviron on Cyclophosphamide-Induced Cardiac Toxicity in Rats. J Evid Based Integr Med. 2018;23:1-11.

37. Yasmeen T, Qureshi GS, Perveen S. Adverse effects of Diclofenac sodium on renal parenchyma of adult albino rats. J Pak Med Assoc. 2007;57:349-51.

38. Adikwu E, Braimbaifa N, Obianime AW. Melatonin and Alpha Lipoic Acid: Possible Mitigants for Lopinavir/ Ritonavir- Induced Renal Toxicity in Male Albino Rats.
Physiol Pharmacol. 2016;19:232-40.

39. Atici S, Cinel I, Cinel L, Doruk N, Eskandari G, Oral U. Liver and kidney toxicity in chronic use of opioids: an experimental long term treatment model. J Biosci. 2005;30:245-52.

40. Cotgreave IA. N-acetylcysteine: pharmacological considerations and experimental and clinical applications. Adv Pharmacol. 1997;38:205-27.

41. Kelman L, Saunders SJ, Frith L, Wicht S, Crrigal A. Effects of dietary protein restriction on albumin synthesis, albumin catabolism, and plasma aminogram. Am J Clin Nutr. 1972;25:1174-8.

42. Patrick L. Nutrients and HIV: part three $\mathrm{N}$-acetylcysteine, alpha-lipoic acid, L glutamine, and L-carnitine. Altern Med Rev. 2000;5:290-305.

43. Cuce G, Esen HH, Koc T, Canbaz HT, Limandal C, Kalkan S, et al. Vitamin E partially ameliorates cyclophosphamide-induced nephrotoxicity in rats. Progress Nutr. 2016;18:140-5.

44. Manda K, Bhatia AL. Prophylactic action of melatonin against cyclophosphamide-induced oxidative stress in mice. Cell Biol Toxicol. 2003;19:367-72.

45. Wen YF, Zhao JQ, Bhadauria M, Nirala SK. Baicalin prevents cadmium induced hepatic cytotoxicity, oxidative stress and histomorphometric alterations. Exp Toxicol Pathol. 2013;65:189-96.

46. Husain F, Arif Maan M, Sheikh MA, Nawaz H, Jamil A. Trace elements status in type 2 diabetes. Bangladesh J Med Sci. 2009;8:52-56.

47. Dobrek L, Skowron B, Baranowska A, Ciesielczyk K, Kopa-Ska M, Thor P. Nephrotoxicity of a single dose of cyclophosphamide and ifosfamide in rats. Acta Poloniae Pharmaceutica - Drug Res. 2017;74:1579-1589.

48. Sangita S, Swarn L, Tiwari KN. The potential protective role of aqueous extract of Aegle marmelos against cyclophosphamide induced nephrotoxicity in mice. J Exp Zool. 2015;18:75-82.

49. El-Naggar SA, Alm-Eldeen AA, Germoush MO, ElBoray KF, Elgebaly HA. Ameliorative effect of propolis against cyclophosphamide-induced toxicity in mice. Pharm Biol. 2015;53:235-41.

50. Honjo I, Suou T, Hirayama C. Hepatotoxicity of cyclophosphamide in man: pharmacokinetic analysis. Res Commun Chem Pathol Pharmacol. 1988;61:149-65.

51. Kehrer JP, Biswal SS. The molecular effects of acrolein. Toxicol Sci. 2000;57:6-15.

52. Abraham P, Indirani K, Sugumar E. Effect of cyclophosphamide treatment on selected lysosomal enzymes in the kidney of rats. Exp Toxicol Pathol. 2007;59:143-9.

53. Sloderbach A, Górska A, Sikorska M, Misiura K, Hładoń B. Klasyczne oksazafosforinany - metabolizm i właściwości terapeutyczne - nowe implikacje (Classical oxazaphosphorines - metabolism and therapeutic properties - new implications). Postepy Hig Med Dosw. 2013;67:1235-1253.

54. Dimari J, Megyesi J, Udvarhelyei N, Price P, Davis R, Safirstein R. N-acetylcysteine ameliorates ischemic renal failure. Am J Physiol. 1997;272:F292-8.

55. Jung KH, Hong SW, Zheng HM, Lee HS, Lee H, Lee 
$\mathrm{DH}$, et al. Melatonin ameliorates cerulein-induced pancreatitis by the modulation of nuclear erythroid 2-related factor 2 and nuclear factor-kappa B in rats. J Pineal Res. 2010;48:239-50.

56. Tavakoli M. Kidney protective effects of melatonin. J Nephropharmacol. 2014;3:7-8.

57. Nava M, Romero F, Quiroz Y, Parra G, Bonet L, Rodri'guez-Iturbe B. Melatonin attenuates acute renal failure and oxidative stress induced by mercuric chloride in rats. Am J Physiol Renal Physiol. 2000;279:F910-8.

58. Gorca A, Huk-Kolega H, Piechota A, Kleniewska P, Ciejka E, Skibska B. Lipoic acid-biological activity and therapeutic potential. Pharmacol Rep. 2011;63:849-58.

59. Moini H, Packer L, Saris NE. Antioxidant and prooxidant activities of alpha-lipoic acid and dihydrolipoic acid. Toxicol Appl Pharmacol. 2002;182:84-90.

Copyright (c) 2019 The Author(s); Published by Published by Society of Diabetic Nephropathy Prevention. This is an open-access article distributed under the terms of the Creative Commons Attribution License (http://creativecommons.org/licenses/by/4.0), which permits unrestricted use, distribution, and reproduction in any medium, provided the original work is properly cited. 